\title{
Vehicle Number Plate Detection and Recognition Techniques: A Review
}

\author{
Shahnaj Parvin, Liton Jude Rozario, Md. Ezharul Islam* \\ Department of Computer Science and Engineering, Jahangirnagar University, Savar, Dhaka-1342, Bangladesh
}

\begin{tabular}{l} 
A R T I C L E I N F O \\
\hline Article history: \\
Received: 07 January, 2021 \\
Accepted: 08 February, 2021 \\
Online: 17 March, 2021 \\
\hline
\end{tabular}

Keywords:

Number plate detection

Number plate recognition

Optical Character Recognition

You Only Look Once (YOLO)

Convolutional Neural Network

Vehicle detection

\section{Introduction}

Vehicle Number Plate Recognition (NPR) or License Plate Recognition (LPR) or Registration Plate Recognition (RPR) is an enhanced computer vision technology that connects vehicles without direct human connection through their number plates [13]. Day by day, the number of vehicles on the road is continuing to grow. For this reason, the news spread almost every day about the vehicle being filched from the parking garage or any other place in the city or having an accident and fleeing. To recognize these vehicles $[4,5]$, authorities should therefore install a number plate detection and recognition device on CCTV at every street corner in every region. This system enhances the police's ability to track illegal activities involving the use of vehicles. NPR systems are effectively used by provincial establishments and manufacturing groups in all facets of safety, inspection, traffic management applications $[6,7]$.

The number plates vary from country to country. There are some rules and regulations for vehicle number plates. Number plate consists of (1) 2 letters (these refer to the region in the country where the vehicle was first registered) (2) 2 numbers (when it was issued) (3) 3 letters chosen at random. Some basic information about vehicle number plates like dimension, styles, and characters

*Corresponding Author: Md. Ezharul Islam, Jahangirnaar University

Email: ezharul.islam@juniv.edu

www.astesj.com

https://dx.doi.org/10.25046/aj060249 of number plates fitted after 1st September 2001 is shown in Figure 1 .

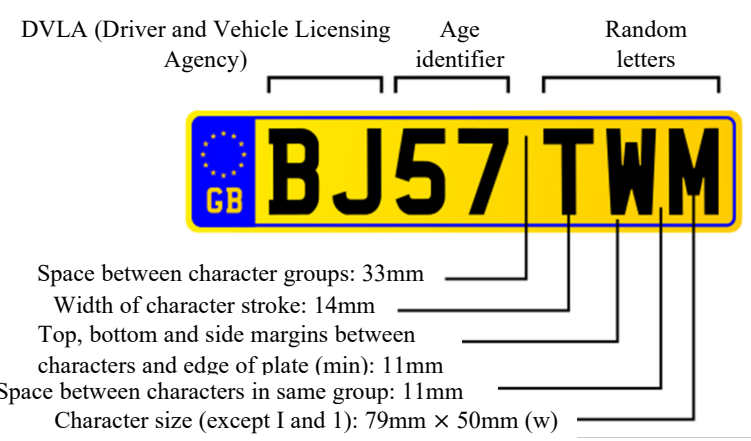

Figure 1: Vehicle number plate fonts and spacing [8]

Some variations are often seen on the vehicle number plates. The difference between American and European number plates is that American vehicle number plates have more things than identification numbers, sometimes little pictures, different color text but in European vehicle plates are used just for identification. Front number plates must show black characters on a white background and the rear number plate must have black letters on a yellow reflective background [8]. The number plates dimension of 
the car and motorcycle in the UK (United Kingdom) is shown in the form of Table 1.

Table 1: Dimension of the vehicle's number plate in UK standard.

\begin{tabular}{|l|c|c|}
\hline \multicolumn{3}{|c|}{ Dimension } \\
\hline \multicolumn{1}{|c|}{ Properties } & Car & Motorcycle \\
\hline Character Height & $79 \mathrm{~mm}$ & $64 \mathrm{~mm}$ \\
\hline Character Width & $50 \mathrm{~mm}$ & $44 \mathrm{~mm}$ \\
\hline Character stroke & $14 \mathrm{~mm}$ & $10 \mathrm{~mm}$ \\
\hline $\begin{array}{l}\text { Space between } \\
\text { characters }\end{array}$ & $11 \mathrm{~mm}$ & $10 \mathrm{~mm}$ \\
\hline $\begin{array}{l}\text { Space between } \\
\text { groups }\end{array}$ & $33 \mathrm{~mm}$ & $30 \mathrm{~mm}$ \\
\hline $\begin{array}{l}\text { Space between } \\
\text { vertical lines }\end{array}$ & $19 \mathrm{~mm}$ & $13 \mathrm{~mm}$ \\
\hline
\end{tabular}

For nearly half a century, vehicle number plate detection, as well as recognition, has been a topic of interest. This technique in the field has opened new challenges. In terms of consistency, color, number plate shape, and type of vehicle, the major challenges of vehicle number plate detection as well as recognition are focused on the various categories of features and are related to changing illumination level, the geometry of visualization, and background [9,10]. In Figure 2, typical samples of vehicle number plates [11] are shown.

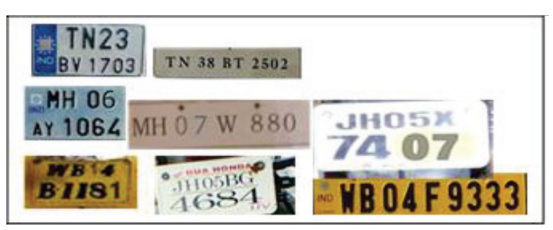

Figure 2: Samples of vehicle number plate [11]

Number plate recognition procedure is divided into three key functions: Identification of Plate Area, Segmentation of Plate Character, and Recognition of Character [12-16]. In terms of traffic management, traffic optimization, traffic law enforcement, vehicle access control, automated collection of tolls, traffic speed control, automatic parking, monitoring of stolen cars, and tracking of possible acts of terrorism, each of these aspects plays a crucial role $[6,7,14,17,18]$.

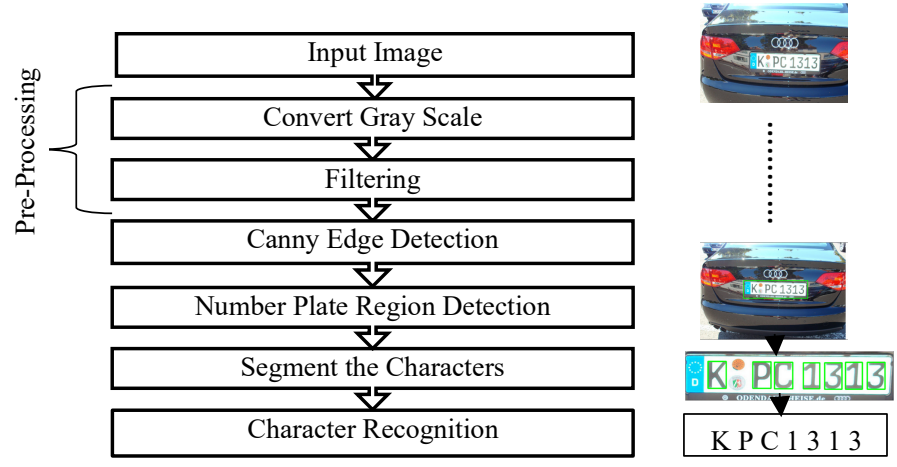

Figure 3: Flow diagram of common number plate detection and recognition method

Figure 3 shows common vehicle number plate detection and recognition method based on the edge detection method. At first, the vehicle registration plate detection as well as the recognition system capture the image using the camera and then apply some image processing techniques for pre-processing the image such as input image to grayscale image conversion, filtering technique to eliminate noise. Next, to extract the license plate area, apply the canny edge detection technique. After that, apply the appropriate detection method to detect the vehicle registration plate effectively, and apply the segmentation technique to segment the characters of the registration plate. Finally, the appropriate character recognition method is used to recognize each of the characters separately.

Due to the lighting conditions, the noisy image captured, fastmoving vehicles, are always a difficult task in vehicle number plate identification as well as recognition. Several researchers have been working on vehicle number plate recognition and are still working in this field. They have adopted several image processing techniques and presented some of their development strategies for vehicle number plate detection. As much research has been done so far in this paper on vehicle number plate detection as well as recognition and their success behind their proposed method and exactly what caused their proposed method to fail is discussed here. And this paper explores how to resolve their limitations or what more can be achieved in this area in the future.

Vehicle number plate detection studies, as well as recognition techniques, have been categorized into three sections in this review paper: (1) Related Works on Vehicle Number Plate Detection Techniques (2) Related Works on Vehicle Number Plate Recognition Techniques (3) Related Works on Vehicle Number Plate Detection as well as Recognition Techniques.

The residual of the paper is arranged in a structured way. The number plate detection strategies are demonstrated in section 2 . Techniques for number plate recognition are discussed in section 3 . In section 4 , techniques of vehicle number plate detection, as well as recognition, are illustrated. Finally, section 5 states the conclusions.

\section{Related Works on Vehicle Number Plate Detection Techniques}

Number plate detection (NPD) is a technology that uses certain image features to understand vehicle registration plates to assess location data for vehicles $[14,19]$. To determine a location going to the next frame, NPD identifies a region of the vehicle number plate with similar structures. The consecutive frame fixes the area of detection in the prior frames with the observed area of the vehicle [20]. During the identification of the registration plate of the vehicle, various difficulties of the surrounding environment were observed. In addition to these, several vehicle number plate considerations are concise in Table 2.

Table 2: Some factors of vehicle number plates [14,21]

\begin{tabular}{l|l}
\hline \multicolumn{1}{c}{$\begin{array}{c}\text { Variants of the number } \\
\text { plates }\end{array}$} & Variants of the environment \\
\hline Plate size & Brightness \\
Plate background & Similarity in background \\
Plate location & \\
Quantity & \\
Font & \\
Angle & \\
Screw & \\
\hline
\end{tabular}


Different researchers have talked about their proposed techniques for identifying vehicle number plates at different times and still a lot of work is being done following their proposed method. Many image processing techniques are existing to detect vehicle number plates such as segmentation, edge detection, color code-based techniques, feature-based techniques, and machine learning techniques. This section discusses different strategies associated with the identification of vehicle number plates. Centered on various methods, the following section is split into several sub-sections.

\subsection{Edge Detection}

In image processing, it is possible to recognize the edges of the image through different edge detection techniques, such as Sobel, Prewitt, Laplacian, and Canny edge band detectors. The Sobel edge detector effectively transforms a compact, detachable, and numeral valued filter to the image in a horizontal and vertical direction. Prewitt is used in frames to detect vertical and horizontal edges. Hence Sobel and Prewitt are kind of similar. Canny edge detector probably the most effective method for complex edge detection. Below, discussed the previous literature of vehicle number plate detection techniques based on edge detection.

In [22], an algorithm has been suggested for vehicle number plate detection in practical situations by Wazalwar. To define the region of interest (ROI), they used the Euler number of a binary image and for edge detection, they used the Mexican hat operator. They have claimed that a license plate had been successfully identified through their suggested technique and their success rate was about $94-99 \%$ and the average accuracy was about $96.17 \%$. Yet there is a situation during their prosperity where they have suffered. The edge detection system fails to properly recognize the edge if the license plate is black.

In [23], a license plate detection system founded on an enhanced Prewitt arithmetic operator has been suggested by Chen under various backgrounds and lighting conditions. The projection method was also carried out horizontally and vertically to change the top and bottom edge areas along the edge to get the vehicle number position. They have achieved $96.75 \%$ precision in their proposed technique, and they have stated that their proposed system meets efficiency in real-time.

An innovative technique for vehicle number plate detection using the special technique of edge detection [24] has been introduced by Tejas. They have used the Sobel edge detection technique to obtain accurate boundaries of the number plate in the image. The system scanned the connected component and then fill them with holes. Thereafter, the system searches the rectangular region that is filled with holes which is probably the size of the license plate and then extracts it. Their proposed system is based on the Internet of Things (IoT). Therefore, online databases have been developed and regularly updated. They have also estimated that the accuracy of their acquisition is around $96.842 \%$. In Figure 4 , their suggested technique is shown.

\subsection{Morphological Operation}

Morphological Operations in image processing attempts to remove these imperfections by considering the image's shape and structure. To reduce noise or to brighten the frame, morphological operations are essentially applied to grayscale images. Morphological operations are referred to as a blend of erosion, dilation, and basic set-theoretical functions, such as a binary image supplement [25]. The corresponding study on morphological operation-based vehicle number plate detection techniques has been discussed below.

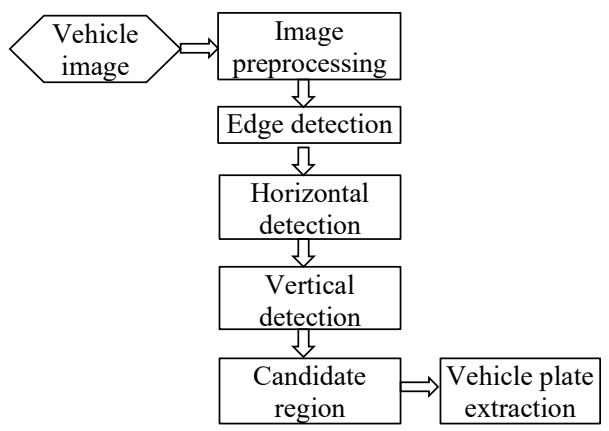

Figure 4: Block diagram of the proposed method [24]

In [26], an existing system used for license plate location on a Raspberry Pi has been improved by the Yepez. Their improved morphological algorithm that reduces computational complexity is based on morphological operations. The strength of this strategy is that the emerging LPR algorithm can operate with the computer as well as low processing power on portable devices. They have also claimed that their enhanced algorithm can detect license plates effectively and have achieved a high precision is about $98.45 \%$. In Figure 5, the flowchart of their proposed method is shown.

\subsection{Convolutional Neural Networks (CNNs)}

A convolutional neural network (CNN) based framework for the detection of vehicle number plate was proposed by the authors in [27]. They have enhanced the existing blurred and obscure image method. They believed that their suggested method effectively detects the number plate of the vehicle under various lighting conditions. The accuracy obtained by their proposed method is around $100 \%$.

\subsection{Machine Learning (ML) based Approaches}

Machine Learning (ML) likewise means that by providing a collection of training data, the machine is trained to do something in image processing. Machine learning has models/architectures, functions of loss, and many methods that can be used to decide which will provide better processing of images. For image enhancement, this approach is commonly applied. The corresponding work of machine learning-based vehicle number plate detection techniques is given below.

In [5], a new technique to detect a vehicle authorization plate has been developed in the Miyata study. The license plate detection technique detects only the edge vertical parts and the candidate license plates that use the contours acquired by dilation and erosion processing and area fill processing. The SVM (Support Vector Machine) has applied to decide whether a license plate is a candidate region or not, and eventually recognizes the location of the license plate. They have claimed that the suggested method efficiently detects license plates and achieved the rate of detection is $90 \%$. 
In [28], an innovative method has been presented for detecting and locating a vehicle's license plate in color images by Yaseen. AdaBoost, a multi-boosting model based on HOG features, is part of the development process. They have claimed that the accuracy achieved by their proposed method is around $89.66 \%$. Figure 6 displays the flow chart of their suggested system.

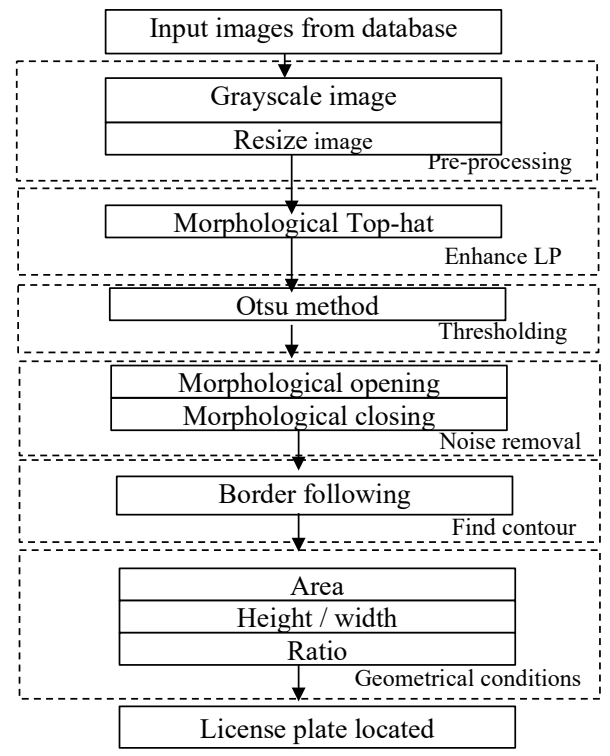

Figure 5: Flowchart of the proposed method [26].

In [29], a vehicle registration plate detection method in the natural image by AdaBoost using the Modified Census Transform (MCT) feature has been suggested by Ban. There are too many noises in the natural image, so detecting the number plate in natural images is too difficult. MCT features, which are robust to illumination change, and AdaBoost for the feature selection to overcome this restriction. They have also reported that the high detection rate achieved by the proposed technique is about $98.7 \%$.

In [30], a systematic style for vehicle registration plate detection applying boosting and part-based models was proposed by Molina-Moreno, which is an algorithm for boosting. They used two datasets and stated that better performance on these datasets was obtained $97.52 \%$ accuracy by their proposed method. With several algorithms, they have also compared their proposed method.

In [31], a novel vehicle number plate detection system has been suggested to improve identification in low lights and over corrosive environments by Babbar. For the extraction of license plates, they used CCA (Connected Component Analysis) and Ratio Analysis (RA). Some OCR strategies have also been used, for example, LR+RF, SVC+KNN, Extra Trees, SVC (Linear, Poly, Rbf, Linear.svc). They stated that the car localization achieved by the developed system is $92.7 \%$ and the segmented characters' accuracy is about $97.1 \%$.

In [32], a KNN (K-nearest Neighbor) machine learning system for automatic vehicle license plate detection was developed by Akshay lepcha. The KNN classifier has been used according to the aspects of the license to retrieve the registration plate from the image. They have also stated that a license plate is correctly identified through their suggested method and achieved an accuracy higher than $90 \%$.
Table 3 provides an overview of the strategies for detecting the vehicle number plate. This table has been sorted based on the year and accuracy.

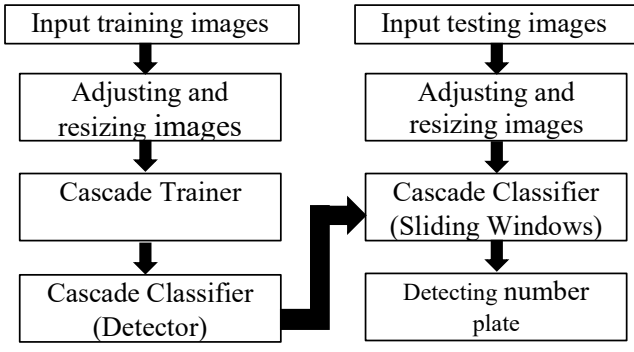

(a) Training phase

(b) Testing phase

Figure 6: Flowchart of the proposed ANPD system [28].

\section{Related Works on Vehicle Number Plate Recognition Techniques}

Vehicle Automatic Number Plate Recognition (ANPR) is a technology applied for the observation as well as recognition of vehicle number plate characters from static and moving vehicle images $[14,28,32,33]$. Due to its effect on the rapid development of traffic monitoring and surveillance [15, 22, 34, 35], vehicle number plate recognition has become a key research field in recent years. For the identification of number plates, several methods are used, such as machine learning, neural networks, BAM (Bidirectional Associative Memories) [35]. Various researchers have given their useful ideas on their proposed vehicle number plate recognition method at various times. In this review paper, various vehicle number plate recognition techniques have been explored. Vehicle number plate recognition techniques have been categorized into some subsections based on distinct approaches in the following section.

\subsection{Neural Network (NN) based Approaches}

Image recognition algorithms in neural networks $(\mathrm{NN})$ can recognize anything, from text to images, audio files, and videos. Neural networks are an interlinked set of neurons or perceptron's called nodes. Each node uses a single input data, generally a single pixel of the image, and uses a simple calculation called an activation function which produces results and each neuron has a numerical score that determines its outcome

\section{Artificial Neural Networks (ANNs)}

In [15], a high-performance-based system for vehicle number plate recognition has been introduced by Türkyilmaz. They have applied edge-based image processing techniques for registration plate detection and have also used a three-layer feedforward artificial neural network for vehicle number plate character recognition using a learning algorithm for back-propagation. The feedforward ANN model for three layers is shown in Figure 7. The input layer receives information from the external environment and transmits it to the nodes (processing units) of the hidden layer without any modification. Network outputs are calculated by processing information in hidden layers and output layers. The most well-known back-propagation learning algorithms are used efficiently at the training stage of this ANN. The authors have verified that the number plate has been successfully identified and recognized by their developed system and their performance rate 
Table 3: Summary of the vehicle number plate detection techniques

\begin{tabular}{|c|c|c|c|c|c|c|}
\hline $\begin{array}{c}\text { First } \\
\text { Author \& } \\
\text { Year }\end{array}$ & $\begin{array}{l}\text { Detection } \\
\text { Methods }\end{array}$ & Datasets & Accuracy & Advantages & Limitations & Future Opportunities \\
\hline $\begin{array}{l}\text { Eswar, } \\
2020[27]\end{array}$ & $\begin{array}{l}\text { Convolution } \\
\text { Neural Network } \\
(\mathrm{CNN})\end{array}$ & $\begin{array}{l}\text { Private } \\
\text { dataset }\end{array}$ & $100 \%$ & $\begin{array}{l}\text { Able to detect } \\
\text { number plate at } \\
\text { different lighting } \\
\text { conditions and } \\
\text { processing time will } \\
\text { be less. }\end{array}$ & & \\
\hline $\begin{array}{l}\text { Molina- } \\
\text { Moreno, } \\
2019[30]\end{array}$ & $\begin{array}{l}\text { Scale-adaptive } \\
\text { deformable part- } \\
\text { based boosting } \\
\text { algorithm }\end{array}$ & $\begin{array}{l}\text { Caltech, } \\
\text { LPR and } \\
\text { MMR } \\
\text { Database }\end{array}$ & $97.52 \%$ & & $\begin{array}{l}\text { The proposed system, } \\
\text { due to the presence of } \\
\text { noise, lack of } \\
\text { lighting, and blurring } \\
\text { of remote license } \\
\text { plates, is not high } \\
\text { enough in many } \\
\text { realistic scenarios. }\end{array}$ & $\begin{array}{l}\text { To improve the } \\
\text { process of } \\
\text { segmentation, } \\
\text { morphological } \\
\text { structures can be } \\
\text { assumed. }\end{array}$ \\
\hline $\begin{array}{l}\text { Yaseen, } \\
2019[28]\end{array}$ & $\begin{array}{l}\text { AdaBoost based } \\
\text { HOG features }\end{array}$ & $\begin{array}{l}\text { North Iraq } \\
\text { Vehicle } \\
\text { Images } \\
\text { (NI-VI) } \\
\text { dataset, }\end{array}$ & $89.66 \%$ & $\begin{array}{l}\text { The dataset must } \\
\text { cover all real-life } \\
\text { vehicle conditions } \\
\text { likely to start, such } \\
\text { as weather } \\
\text { conditions, size, } \\
\text { color, and license } \\
\text { plates. }\end{array}$ & & $\begin{array}{l}\text { This dataset can be } \\
\text { further used for } \\
\text { Automatic Number } \\
\text { Plate Recognition } \\
\text { systems. }\end{array}$ \\
\hline $\begin{array}{l}\text { Yepez, } \\
2018[26]\end{array}$ & $\begin{array}{l}\text { Morphological } \\
\text { opeartions }\end{array}$ & $\begin{array}{l}\text { MediaLab } \\
\text { LPR } \\
\text { database }\end{array}$ & $98.45 \%$ & $\begin{array}{l}\text { Able to work on } \\
\text { both a computer and } \\
\text { low power portable } \\
\text { device. }\end{array}$ & & $\begin{array}{l}\text { Any other image } \\
\text { processing technique } \\
\text { can be applied for } \\
\text { further improvement. }\end{array}$ \\
\hline $\begin{array}{l}\text { Babbar, } \\
2018[31]\end{array}$ & $\begin{array}{l}\text { CCA, Ratio } \\
\text { analysis, } \\
\text { LR+RF, } \\
\text { SVC+KNN, } \\
\text { Extra Trees, } \\
\text { SVC (Linear, } \\
\text { Poly, Rbf, } \\
\text { Linear.svc) }\end{array}$ & $\begin{array}{l}\text { Vehicles } \\
\text { at JIIT } \\
\text { institution }\end{array}$ & $\begin{array}{l}\text { Detection } \\
\text { rate } \\
92.7 \% \\
\text { accuracy } \\
97.1 \%\end{array}$ & $\begin{array}{l}\text { The system is } \\
\text { successfully } \\
\text { detecting number } \\
\text { plates from skewed } \\
\text { angles. }\end{array}$ & & $\begin{array}{l}\text { Perhaps this system } \\
\text { can be improved by } \\
\text { locating the reversed } \\
\text { vehicle number plate } \\
\text { in the event of an } \\
\text { accident and warning } \\
\text { the nearest hospital } \\
\text { and policing station } \\
\text { of the accident, thus } \\
\text { saving lives. }\end{array}$ \\
\hline $\begin{array}{l}\text { Akshay } \\
\text { lepcha, } \\
2018 \text { [32] }\end{array}$ & KNN Classifier & $\begin{array}{l}\text { Their own } \\
\text { dataset } \\
\text { with } \\
\text { videos }\end{array}$ & $\begin{array}{l}\text { Higher } \\
\text { than } 95 \%\end{array}$ & $\begin{array}{l}\text { Improved } \\
\text { performance is } 11 \% \text {. }\end{array}$ & & \\
\hline $\begin{array}{l}\text { Tejas, } \\
2017[24]\end{array}$ & $\begin{array}{l}\text { Sobel edge } \\
\text { detector }\end{array}$ & $\begin{array}{l}\text { Their own } \\
\text { dataset }\end{array}$ & $96.842 \%$ & $\begin{array}{l}\text { Proposed system } \\
\text { makes easier to } \\
\text { update database. }\end{array}$ & & $\begin{array}{l}\text { Genetic algorithm can } \\
\text { be applied for better } \\
\text { performance and web } \\
\text { application can be } \\
\text { integrated. }\end{array}$ \\
\hline $\begin{array}{l}\text { Miyata, } \\
2016[5]\end{array}$ & $\begin{array}{l}\text { Support Vector } \\
\text { Machine (SVM) }\end{array}$ & $\begin{array}{l}\text { Their own } \\
\text { dataset } \\
\text { with } 100 \\
\text { images. }\end{array}$ & $90 \%$ & & $\begin{array}{l}\text { The detection rate is } \\
\text { significantly } \\
\text { influenced by the } \\
\text { luminosity of the } \\
\text { body of the vehicle } \\
\text { license plate. }\end{array}$ & $\begin{array}{l}\text { The detection rate can } \\
\text { be increased by } \\
\text { improving brightness } \\
\text { or other features. }\end{array}$ \\
\hline $\begin{array}{l}\text { Chen, } \\
2012 \text { [23] }\end{array}$ & $\begin{array}{l}\text { Prewitt operator } \\
\text { for edge } \\
\text { detection }\end{array}$ & & $96.75 \%$ & $\begin{array}{l}\text { Suggested system } \\
\text { performs in real- } \\
\text { time. }\end{array}$ & & $\begin{array}{l}\text { Different edge } \\
\text { detection method can } \\
\text { be used. }\end{array}$ \\
\hline
\end{tabular}




\begin{tabular}{|l|l|l|l|l|l|l|}
\hline $\begin{array}{l}\text { Ban, 2012 } \\
\text { [29] }\end{array}$ & $\begin{array}{l}\text { AdaBoost based } \\
\text { on Modified } \\
\text { Census } \\
\text { Transform } \\
\text { (MCT) features }\end{array}$ & $\begin{array}{l}\text { Their own } \\
\text { dataset } \\
\text { with 3373 } \\
\text { LP } \\
\text { images }\end{array}$ & $98.7 \%$ & & $\begin{array}{l}\text { Proposed method is } \\
\text { failed to detect the } \\
\text { numbers, which have } \\
\text { different width/height } \\
\text { ratio when the } \\
\text { training stage. }\end{array}$ & $\begin{array}{l}\text { The shortcomings can } \\
\text { be improved in the } \\
\text { future. }\end{array}$ \\
\hline $\begin{array}{l}\text { Wazalwar, } \\
2011[22]\end{array}$ & $\begin{array}{l}\text { Mexican hat } \\
\text { operator for edge } \\
\text { detection }\end{array}$ & $\begin{array}{l}\text { Medialab } \\
\text { LPR } \\
\text { Database }\end{array}$ & $96.17 \%$ & & $\begin{array}{l}\text { Black license plate } \\
\text { cannot detect the } \\
\text { edge properly. }\end{array}$ & $\begin{array}{l}\text { Motion analysis can } \\
\text { be applied to } \\
\text { overcome failure. }\end{array}$ \\
\hline
\end{tabular}

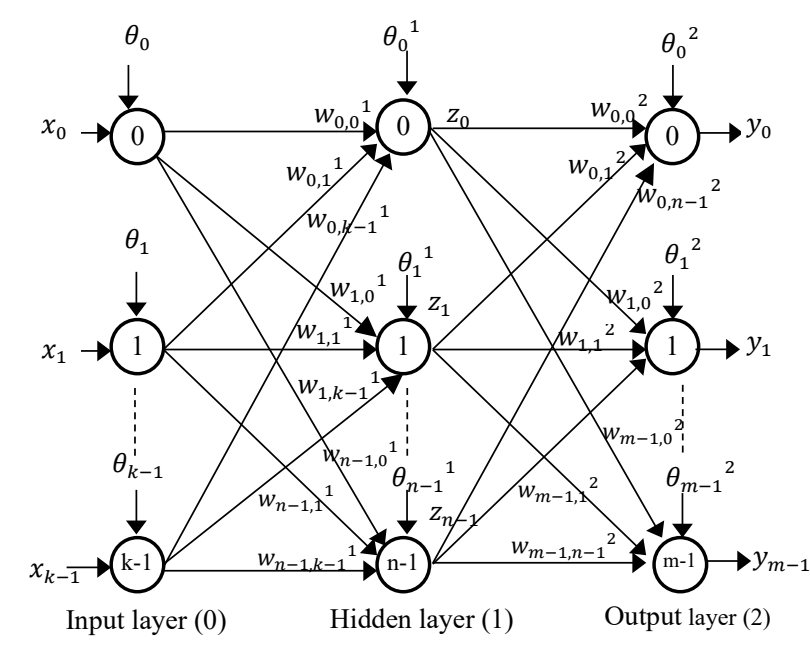

Figure 7: Three-layer feedforward ANN model [15]

\section{Convolutional Neural Networks (CNNs)}

CNN is familiar to describe the characters that appear in the segmented License plates (LPs). CNN consists of, as seen in Figure 8, a set of layers of conv (Convolution), pooling, and fully connected (FC) layers [36].

In [11], a system for automatic number plate recognition applying convolutional neural networks (CNN) centered on selfsynthesized features was proposed by Mondal. The selfsynthesized feature of CNN can recognize the states of the vehicle from the number plate. They have confirmed that their system is robust and effective with accurate identification of the license plate of the vehicle from the images above $90 \%$.
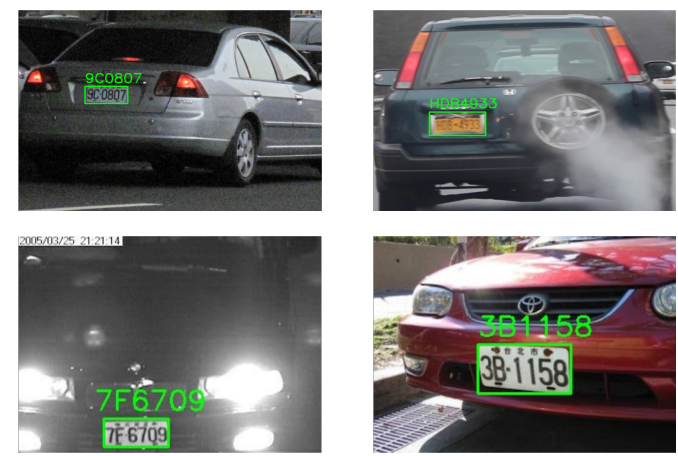

Figure 9: Vehicle number plate recognition results using dataset [37].

In [37], a set of vehicle number plate recognition techniques has suggested by Yang. They have first introduced a contour reconstruction method with edge-detection to accurately detect the number plates and then used a zero-one-alternation technique to effectively remove the misleading top and bottom borders around plates to allow more precise character segmentation on plates. Subsequently, for character recognition, a convolutional neural network (CNN) was applied. Furthermore, the SIFT (Scale Invariant Feature Transform) feature has been used in CNN for successful training. SIFT is a feature detection algorithm and it helps to locate the local features in an image. Finally, a two-phase verification approach has been implemented, the first phase is a statistical filter in the LPD phase to effectively remove the wrong plates and the second phase is shortening the system pipeline, which increases the LPDR system's performance. They have confirmed that the intended method essentially recognizes the vehicle number plate in real time and achieved a precision rate is about $84.3 \%$. Figure 9 displays the recognition results of the proposed system.

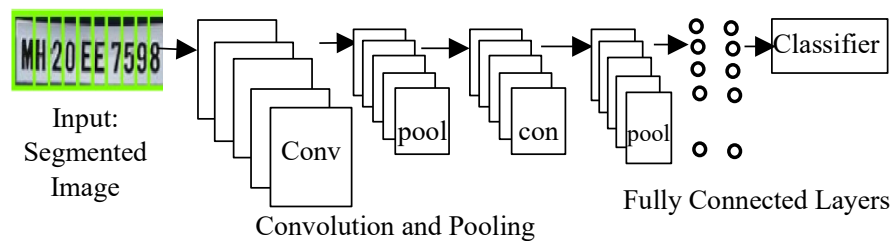

Figure 8: The design of CNN for character recognition [36].

In [38], an interference occurrence on CNN classifiers in the License Plate Recognition Systems (LPR) was introduced in the study of Qian, which adds pre-arranged alarms to definite parts of license plate images, pretending to have indeed formed spots. They have used the genetic algorithm technique to enhance the difficult issues. During vehicle number plate identification, spots that are not usually accessible to humans will be at great risk at any point. They have argued that they were able to identify the number plate character effectively despite getting several spots and their performance rate is $93 \%$.

In [39], a framework for the identification of vehicle license plates on urban roads focused on vehicle tracking and data integration was implemented by Zhu. An object detection framework is trained, centered on a plate detector, to detect each vehicle's license plate from the video series. The convolutional neural networks $(\mathrm{CNN})$ have been applied for vehicle registration plate recognition from the video sequences. Besides, the continuous frames have combined recognition effects to achieve the result. The proposed LPR system layout focusing on vehicle tracking and outcome incorporation is shown in Figure 10. They claimed that under the real urban road climate, their license plate detection accuracy and recall were $82.5 \%$ and $89 \%$ respectively. 


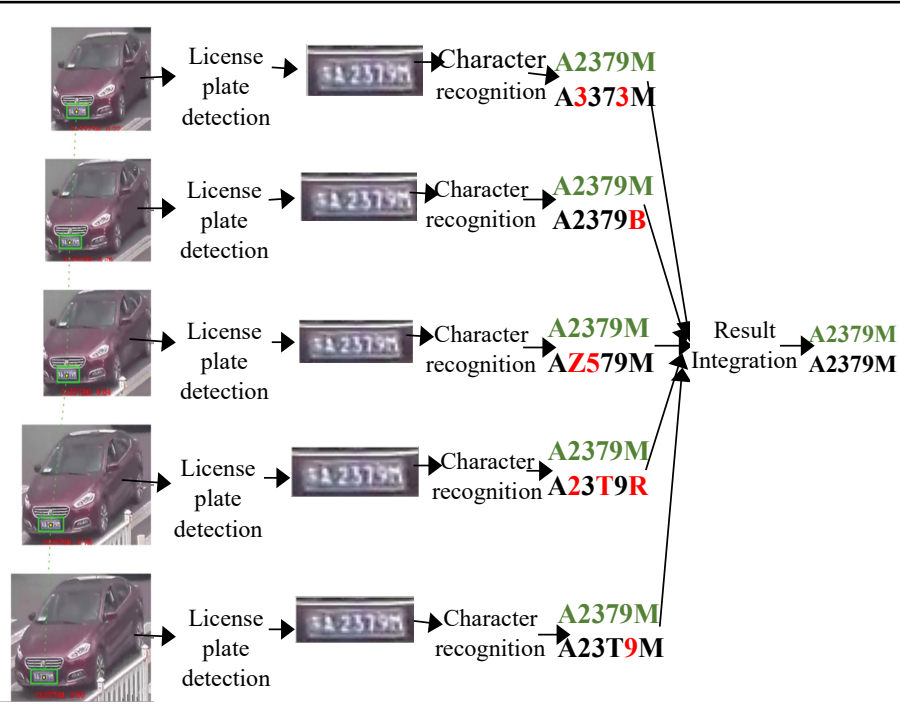

Figure 10: Structure of the LPR system centered on vehicle tracking and result integration [39].

In [40], the authors presented a system of image de-noise supportive of defining the license plate of the vehicle. They also combined a new de-noising and rectification approach conducted by CNN that focuses on jointly solving both problems. They argued that their proposed approach effectively recovers the image issues of the low-quality license plate and identifies the character successfully. They claimed that their proposed method achieves 93.08\% accuracy for detecting the license plate.

\section{Generative Adversarial Networks (GANs)}

In [41], a new method of making text images of high-resolution license plates has been introduced by Gupta where the style and textual content of the images are parametrically represented. To acquire the conditional generation of photo-realistic images, the proposed system combines text to image recovery techniques with Progressive Growing of Generative Adversarial Networks (PGGANs). They have used the American license plate dataset for the proposed system and achieved higher accuracy to recognize the registration plate characters.

In [42], a method of registration plate recognition for speeding vehicles using a motion camera was proposed by Wang, implying whether something is feasible to create synthetic training data using GAN to enhance identification precision. They used a Deep Convolutional Neural Network (DCNN) accompanied by a longterm short-term memory (LSTM), Bidirectional Recurrent Neural Network (BRNN), which performs the learning function and sequence labeling. They reported that the recognition accuracy achieved by the proposed system was $89.4 \%$ for moving cars on demanding test datasets.

In [43], a method for registration plate recognition in the natural environment has been suggested by Zhang. Their suggested method contains a customized model of Cycle GAN for license plate image generation. They have employed a $2 \mathrm{D}$ attention plate recognizer with an Xception-based CNN encoder which can reliably and efficiently differentiate license plates with different designs. Four datasets were also used by them to assess the efficiency of their proposed framework and achieved an accuracy higher than $80 \%$.

\section{Recurrent Neural Networks (RNNs)}

In [44], a combined ConvNet-RNN model was developed by Cheang to identify legitimate captured registration plate images. To develop feature extraction, a Convolutional Neural Network (ConvNet) is included. For computation, a Recurrent Neural Network (RNN) has been applied. They tackled this problem by promoting the whole image as a contribution to ConvNet, sliding windows could not access the whole image context. They have confirmed that the combined model achieved over $76 \%$ accuracy in recognizing the license plate characters in their dataset, with a per-character accuracy of $95.1 \%$.

\subsection{Computer Vision $(\mathrm{CV})$}

In [45], an algorithm based on computer vision technology for automatic vehicle license plate recognition has been introduced by Akila. The suggested system addresses various lighting conditions by capturing the image file collected at different times. They used Optical Character Recognition (OCR) to retrieve the numbers from the number plate. They have tested their proposed system for different data with different characteristics of number plates, such as black, inverted color, bold or stylish pattern. Recursive subdivisions have been used to extract character image features. They have stated that the proposed system was successfully identical, extracted, and segmented by the license plate, and achieved a higher, good, and acceptable rate.

\subsection{YOLO (You Only Look Once)}

YOLO is an actual algorithm for object detection, among the most effective and significant object detection algorithms, which integrates several pioneering ideas in computer vision from the scientific community [46]. All of the previous algorithms for object detection use regions to locate the object within the image. YOLO greatly differs from region-based algorithms. The bounding boxes and the class probabilities for these boxes are predicted by a single convolutional network in YOLO. YOLO is faster (it can deal with 45 frames per second) than other algorithms for object detection. But the YOLO algorithm is limited by the fact that it manages with small objects within the image.

In [47], a robust and efficient YOLO object detector-based ALPR system has been implemented by Laroca. They have used an inverted License Plates (LPs) system for the segmentation and identification of characters applying basic techniques for data improvement. Both Fast-YOLO and YOLOv2 models were evaluated at this point to be able to handle simpler (i.e., SSIG) and more realistic (i.e., UFPR-ALPR) data. For simpler situations, Fast-YOLO should be able to correctly detect vehicles and their LPs in a much shorter time. The resulting ALPR process has also obtained crucial results in two datasets. They reported that their system achieved a recognition rate of $93.53 \%$.

In [48], an efficient and effective YOLO object detector-based layout-independent Automatic License Plate Recognition (ALPR) framework has been suggested by Laroca that includes a coherent technique for detection and layout classification of license plate (LP). In their proposed ALPR system, they performed experiments with the Fast-YOLOv2 and Fast-YOLOv3 models. In the validation set, Fast-YOLOv2 obtained slightly better results than its successor. This is since YOLOv3 and FastYOLOv3 have 
relatively high performance on small objects but comparatively worse performance on medium and larger size objects. Eight public datasets were used by them and many data augmentation techniques were used on the datasets. They have confirmed that an overall identification rate of $96.8 \%$ on the datasets was reached by the proposed method.

In [49], an inventive vehicle license plate location system using the latest YOLO-L model and pre-identification plate was developed by Min. The proposed model modifies two parts to discover the area of the license plate precisely. The k-means++ clustering algorithm was first used to choose the appropriate size and amount of the candidate boxes for a plate. Next, the YOLOv2 network model and depth were amended. To separate license plates from related items, they also used a plate pre-identification algorithm. They have claimed that precision of $98.86 \%$ and a recall of $98.86 \%$ were achieved by the proposed method.

In [50], a global vehicle license plate recognition scheme has been suggested by Henry. The intended method was founded on the YOLOv3 networks. The suggested system consists of three key steps: 1) identification of License Plate (LP), 2) recognition of unified characters, and 3) detection of global LP layouts. They used their Korean dataset to test their success and used the dataset of the other four countries. They have confirmed that the proposed ALPR method consumes an average of around $42 \mathrm{~ms}$ per image to extract the number of LPs and achieves an accuracy of up to $90 \%$.

\subsection{Deep Learning (DL) based Approaches}

In [51], a system for vehicle license plate recognition in complex environments using a deep learning approach was suggested by Weihong. First, more sophisticated algorithms for key issues such as skewing of the license plate, image noise, and blurring of license plate were implemented. Then the deep learning algorithms were listed as algorithms for direct detection and indirect detection, and the detection and recognition of license plates and algorithms were analyzed. Besides, contrasts were made between the variations in data sets, workstations (special computers that provide higher performance, graphics, memory space, and multitasking capabilities), precision, and time complexity of various license plate recognition systems. Finally, the existing public datasets of license plates were compared and illustrated as per the set of images, the resolution, and the sophistication of the area. They reported that their model achieved a segmentation rate of $82.6 \%$ and recognition precision of $87.3 \%$.

In [52], an innovative deep learning-based vehicle registration plate recognition approach for general road surveillance cameras is presented by Elihos. In the character detection and recognition process, the suggested free segmentation license plate recognition technique employs deep learning object detection techniques. They used their private dataset containing 2000 images captured on a highway, which were tested. They also stated that the overall accuracy of the proposed achievement is $73.3 \%$.

In [53], an SSD (Single Shot Detector) based natural environment registration plate recognition system has been suggested by Yao. The proposed LPR-SSD network is composed of two networks centered on SSDs. The proposed method is subdivided into two sections. The first part consists of locating and classifying the plate detection, and the second part is to locate and identify character recognition. They reported that the LPR-SSD achieved a greater acceleration in testing and the accuracy of identification and classification of license plate location exceeded $98.3 \%$ and the accuracy rate of character recognition exceeded $99.1 \%$.

\subsection{Image Processing Techniques}

\section{Edge-based Approach}

In [54], a system for automatic license plate recognition founded on integrated edge-based Connected Component Analysis (CCA) techniques was proposed by Arafat where license plate identification, segmentation, and recognition of different shapes have focused. They ensured that better character segmentation was accomplished by the proposed approach and that $96.5 \%, 95.6 \%$, and $94.4 \%$ were correct for identification, segmentation, and recognition respectively.

\section{Gradient Segmentation}

In [55], a system for vehicle license plate tracking through gradient-based segmentation was developed by Kumar. Gradientbased segmentation adjusts the lighting level of the image to ascertain the position of the license plate. The proposed approach filters the region of interest using the Hue, Saturation, and Value (HSV). They also ensured that the proposed system accurately tracks the vehicle's license plate to recognize the registration plate characters and achieved the precision is about $94 \%$.

\section{Optical Character Recognition (OCR)}

In [56], an automated number plate recognition system manipulating image processing techniques was introduced by Kashyap. To recognize the characters on the license plate, Optical Character Recognition (OCR) converted the lettering on the number plate image to text. They have achieved accuracy is about $82.6 \%$.

In [57], an effective process for automatic license plate recognition was intended by Pechiammal. The proposed method consists of three portions: segmentation of characters, identification of optical characters, and matching of models. They have demonstrated that the suggested method effectively extracts character from the plate and $85 \%$ is the extraction rate.

In [58], an innovative vehicle number plate recognition method using OCR and template matching strategies for the Pakistani language has been suggested by Rehman. Several real-time images from different formats of number plates used in Pakistan were evaluated by the proposed ANPR system. They stated that for law enforcement agencies and private organizations to enhance home security, the ANPR model has both time and money-saving profit. They reported that $93 \%$ accuracy of their proposed ANPR approach was achieved. This system can be further expanded to identify the number plate of the crashed vehicle in an accident and warn the nearest hospital and police station about the accident, thereby protecting the number plate of the accident.

\subsection{Feature Extraction Technique}

In [59], an innovative method was intended for the framework of vehicle registration plate recognition based on compressive sensing techniques using reduction of dimensionality and 
extraction of features by Joki'c. To extract the features, they used the Support Vector Machine (SVM). They announced that the proposed method has achieved an average accuracy is about $98.81 \%$.

\subsection{K-means Clustering-based Approach}

In [36], an efficient deep learning-based approach to recognition plate for vehicles, including appropriate optimal Kmeans clustering segmentation and Convolutional Neural Network $(\mathrm{CNN})$, was implemented in the research of Pustokhina. Optimal $\mathrm{K}$-means clustering is used for segmenting the license plate and a Convolutional Neural network is used for recognizing the license plate characters. The Bernsen Algorithms (IBA) and the Connected Component Analysis (CCA) models were used to classify and locate the license plates. They have reported that the maximum accuracy obtained by the proposed Optimal K-Means with Convolutional Neural Network (OKM-CNN) system on the datasets is about $98.1 \%$.

\subsection{Genetic Algorithm (GA) based Approach}

In [60], introduced the latest approach to image-processing algorithms and the optimized genetic algorithm (GA) of the Neutrosophic Set (NS) by Yousif. Certain techniques including edge detection and morphological localization were initially introduced. Besides, they also used a new method using a new approach to optimize the (NS) operations for extracting the most salient features (GA). Furthermore, the clustering algorithm kmeans was introduced for the segmentation of (LP) characters. Finally, the Connected Components Labeling Analysis (CCLA) algorithm has been used to identify the associated pixel domains and the labeling accuracy obtained by the efficiency of the suggested new method was $96.67 \%$ for Arabic-Egyptian (LP) and $94.27 \%$ for English (LP) and that the computations in both databases had an estimated completion time of approximately 0.996 seconds. Language is the most important factor to recognize characters. Each researcher uses different methods for the different languages for which the recognition rate varies. But English is the common language, and a very good number of techniques for English language recognition compared to other languages. Although the Arabic-Egyptian language is harder to recognize than English, the reason for the higher recognition rate is the image resolution.

Table 4 provides an overview of the techniques used to recognize vehicle number plates. This table has been sorted based on the year and accuracy.

Table 4: Summary of the proposed vehicle license plate recognition methods.

\begin{tabular}{|c|c|c|c|c|c|c|c|}
\hline $\begin{array}{c}\text { First } \\
\text { Author } \\
\& \text { Year }\end{array}$ & $\begin{array}{l}\text { Recognition } \\
\text { Methods }\end{array}$ & $\begin{array}{l}\text { Recognition } \\
\text { Character }\end{array}$ & Datasets & Accuracy & Advantages & Limitations & $\begin{array}{c}\text { Future } \\
\text { Opportunities }\end{array}$ \\
\hline $\begin{array}{l}\text { Pustokhi } \\
\text { na, } 2020 \\
{[36]}\end{array}$ & $\begin{array}{l}\text { OKM-CNN, } \\
\text { Improved } \\
\text { Bernsen } \\
\text { Algorithm } \\
\text { (IBA), CCA }\end{array}$ & English & $\begin{array}{l}\text { Stanford } \\
\text { Cars, FZU } \\
\text { Cars and } \\
\text { HumAIn. }\end{array}$ & $98.1 \%$ & $\begin{array}{l}\text { Performs in } \\
\text { real time. }\end{array}$ & & $\begin{array}{l}\text { Multilingual LPs } \\
\text { can be increased to } \\
\text { recognize the } \\
\text { efficiency of the } \\
\text { OKM-CNN model. }\end{array}$ \\
\hline $\begin{array}{l}\text { Yousif, } \\
2020 \\
{[60]}\end{array}$ & $\begin{array}{l}\text { Neutrosophic set } \\
\text { (NS) based } \\
\text { Genetic } \\
\text { Algorithm (GA), } \\
\text { K-means } \\
\text { Clustering, } \\
\text { CCLA, edge } \\
\text { detection }\end{array}$ & $\begin{array}{l}\text { Arabic - } \\
\text { Egyptian, } \\
\text { English }\end{array}$ & $\begin{array}{l}\text { Private } \\
\text { dataset, } \\
\text { Media Lab } \\
\text { benchmark } \\
\text { LP and } \\
\text { AOLP } \\
\text { benchmark } \\
\text { LP dataset }\end{array}$ & $\begin{array}{l}96.67 \% \\
\text { for } \\
\text { Egyptian } \\
\text { and } \\
94.27 \% \\
\text { for } \\
\text { English }\end{array}$ & $\begin{array}{l}\text { Easily } \\
\text { recognizes } \\
\text { Arabic or } \\
\text { Egyptian } \\
\text { characters } \\
\text { as well as } \\
\text { English } \\
\text { characters. }\end{array}$ & & $\begin{array}{l}\text { Optimization } \\
\text { techniques such as } \\
\text { particle swarm, ant } \\
\text { colony, chicken } \\
\text { swarm, and fuzzy } \\
\text { techniques can be } \\
\text { added. }\end{array}$ \\
\hline $\begin{array}{l}\text { Arafat, } \\
2020 \\
{[54]}\end{array}$ & $\begin{array}{l}\text { Connected } \\
\text { component } \\
\text { analysis, } \\
\text { integrated } \\
\text { edge based } \\
\text { technique }\end{array}$ & English & $\begin{array}{l}\text { Malaysian } \\
\text { LPs }\end{array}$ & $94.4 \%$ & $\begin{array}{l}\text { For real- } \\
\text { time } \\
\text { application } \\
\mathrm{s} \text {, this } \\
\text { technique } \\
\text { is useful. }\end{array}$ & & $\begin{array}{l}\text { In the future, it is } \\
\text { possible to } \\
\text { recognize font } \\
\text { similarity issues in } \\
\text { LP characters using } \\
\text { the DL architecture. }\end{array}$ \\
\hline $\begin{array}{l}\text { Rehman, } \\
2020 \\
{[58]}\end{array}$ & $\begin{array}{l}\text { OCR, Template } \\
\text { Matching }\end{array}$ & Pakistani & $\begin{array}{l}\text { Private } \\
\text { Dataset } \\
\text { contains } 900 \\
\text { images }\end{array}$ & $93 \%$ & & $\begin{array}{l}\text { The } \\
\text { identification rate } \\
\text { of their proposed } \\
\text { scheme is lower } \\
\text { for unclear } \\
\text { plates, blurring } \\
\text { and non-standard } \\
\text { vehicle number } \\
\text { plates. }\end{array}$ & $\begin{array}{l}\text { The accuracy can } \\
\text { be improved, and } \\
\text { this system can be } \\
\text { further expanded to } \\
\text { identify the number } \\
\text { plate of the crashed } \\
\text { vehicle }\end{array}$ \\
\hline
\end{tabular}




\begin{tabular}{|c|c|c|c|c|c|c|c|}
\hline $\begin{array}{l}\text { Henry, } \\
2020 \\
{[50]}\end{array}$ & $\begin{array}{l}\text { YOLOv3 } \\
\text { Networks }\end{array}$ & $\begin{array}{l}\text { Korean and } \\
\text { English }\end{array}$ & $\begin{array}{l}\text { KarPlate, } \\
\text { AOLP, Caltech } \\
\text { Cars, Medialab } \\
\text { LPR, University } \\
\text { of Zagreb }\end{array}$ & $\begin{array}{l}\text { Higher } \\
\text { than } \\
90 \%\end{array}$ & $\begin{array}{l}\text { The proposed } \\
\text { scheme is } \\
\text { applicable to } \\
\text { the license } \\
\text { plate for } \\
\text { vehicles in } \\
\text { several } \\
\text { countries. }\end{array}$ & & \\
\hline $\begin{array}{l}\text { Weihong } \\
\text {,2020 } \\
{[51]}\end{array}$ & $\begin{array}{l}\text { Deep learning } \\
\text { approaches }\end{array}$ & $\begin{array}{l}\text { English and } \\
\text { Chinese }\end{array}$ & $\begin{array}{l}\text { Caltech Car, } \\
\text { English LP, } \\
\text { Chinese LP, } \\
\text { UFPR-ALPR }\end{array}$ & $87.3 \%$ & & & $\begin{array}{l}\text { An algorithm with } \\
\text { an image } \\
\text { deblurring and } \\
\text { plate correction } \\
\text { can be } \\
\text { implemented, or } \\
\text { the license plate } \\
\text { detection rate can } \\
\text { be increased. }\end{array}$ \\
\hline $\begin{array}{l}\text { Zhang, } \\
2020 \\
{[43]}\end{array}$ & $\begin{array}{l}\text { CycleGAN } \\
\text { model, } \\
\text { Xception-based } \\
\text { CNN encoder }\end{array}$ & Chinese & $\begin{array}{l}\text { CCPD, AOLP, } \\
\text { PKUData, } \\
\text { CLPD }\end{array}$ & $\begin{array}{l}\text { More } \\
\text { than } \\
80 \%\end{array}$ & & $\begin{array}{l}\text { Images with } \\
\text { extreme blur or } \\
\text { occlusion are } \\
\text { unable to } \\
\text { recognize. }\end{array}$ & $\begin{array}{l}\text { A transformer- } \\
\text { like decoder may } \\
\text { be explored to } \\
\text { accelerate training } \\
\text { speed. }\end{array}$ \\
\hline $\begin{array}{l}\text { Yao, } \\
2019 \\
{[53]}\end{array}$ & $\begin{array}{l}\text { SSD based } \\
\text { approach }\end{array}$ & Chinese & $\begin{array}{l}\text { Their own } \\
\text { dataset contains } \\
16 \text { types of } \\
\text { license plates }\end{array}$ & $99.1 \%$ & $\begin{array}{l}\text { Efficiency of } \\
\text { the proposed } \\
\text { system is real } \\
\text { timing. }\end{array}$ & & \\
\hline $\begin{array}{l}\text { Joki'c, } \\
2019 \\
{[59]}\end{array}$ & $\begin{array}{l}\text { Compressive } \\
\text { Sensing } \\
\text { Technique, } \\
\text { SVM }\end{array}$ & English & $\begin{array}{l}\text { Character } \\
\text { Image set in CV } \\
\text { toolbox for } \\
\text { matlab }\end{array}$ & $98.81 \%$ & $\begin{array}{l}\text { The proposed } \\
\text { system has } \\
\text { great } \\
\text { performance } \\
\text { in } \\
\text { classification. }\end{array}$ & & \\
\hline $\begin{array}{l}\text { Laroca, } \\
2019 \\
{[48]}\end{array}$ & $\begin{array}{l}\text { Fast-YOLOv2 } \\
\text { and Fast- } \\
\text { YOLOv3 } \\
\text { models. }\end{array}$ & $\begin{array}{c}\text { Chinese } \\
\text { and English }\end{array}$ & $\begin{array}{l}\text { Caltech Cars, } \\
\text { EnglishLP, } \\
\text { UCSD-Stills, } \\
\text { ChineseLP, } \\
\text { AOLP, } \\
\text { OpenALPR- } \\
\text { EU, SSIG- } \\
\text { SegPlate, } \\
\text { UFPR-ALPR }\end{array}$ & $96.8 \%$ & $\begin{array}{l}\text { Proposed } \\
\text { system } \\
\text { achieved an } \\
\text { impressive } \\
\text { trade-off } \\
\text { between } \\
\text { accuracy and } \\
\text { speed. }\end{array}$ & & $\begin{array}{l}\text { Further } \\
\text { optimization the } \\
\text { system can be } \\
\text { used a new CNN } \\
\text { architecture. }\end{array}$ \\
\hline $\begin{array}{l}\text { Kumar, } \\
2019 \\
{[55]}\end{array}$ & $\begin{array}{l}\text { Gradient based } \\
\text { Segmentation, } \\
\text { Edge detection } \\
\text { techniques }\end{array}$ & English & $\begin{array}{l}\text { Their own } \\
\text { dataset contains } \\
78 \text { images. }\end{array}$ & $94.87 \%$ & $\begin{array}{l}\text { This system } \\
\text { to be helpful } \\
\text { for the } \\
\text { security of } \\
\text { the vehicles. }\end{array}$ & $\begin{array}{l}\text { This system } \\
\text { could not } \\
\text { extract the } \\
\text { license plate } \\
\text { with a yellow } \\
\text { base. }\end{array}$ & $\begin{array}{l}\text { This technique } \\
\text { can be applied for } \\
\text { any type of } \\
\text { character } \\
\text { segmentation and } \\
\text { recognition. }\end{array}$ \\
\hline $\begin{array}{l}\text { Lee, } \\
2019 \\
{[40]}\end{array}$ & $\begin{array}{l}\text { Image De- } \\
\text { noising, } \\
\text { Rectification, } \\
\text { CNN }\end{array}$ & English & $\begin{array}{l}\text { AOLP-RP and } \\
\text { VTLPs dataset }\end{array}$ & $93.08 \%$ & & $\begin{array}{l}\text { Some cases } \\
\text { LPR makes a } \\
\text { mistake in } \\
\text { detection and } \\
\text { classification. }\end{array}$ & $\begin{array}{l}\text { Adjacent context } \\
\text { can be added in } \\
\text { the future. }\end{array}$ \\
\hline $\begin{array}{l}\text { Zhu, } \\
2019 \\
{[39]}\end{array}$ & $\begin{array}{l}\text { Convolutional } \\
\text { Neural } \\
\text { Networks } \\
(\mathrm{CNN}) \\
\end{array}$ & Chinese & $\begin{array}{l}\text { Their own } \\
\text { dataset, } \\
\text { contains } 19020 \\
\text { images }\end{array}$ & $82.5 \%$ & $\begin{array}{l}\text { This method } \\
\text { is feasible } \\
\text { and accurate } \\
\text { in real time. }\end{array}$ & & $\begin{array}{l}\text { Performance can } \\
\text { be further } \\
\text { improved. }\end{array}$ \\
\hline
\end{tabular}




\begin{tabular}{|c|c|c|c|c|c|c|c|}
\hline $\begin{array}{l}\text { Elihos, } \\
2019 \text { [52] }\end{array}$ & $\begin{array}{l}\text { Deep learning } \\
\text { techniques }\end{array}$ & English & $\begin{array}{l}\text { Private } \\
\text { dataset }\end{array}$ & $73.3 \%$ & & $\begin{array}{l}\text { In weak } \\
\text { character } \\
\text { signals, the } \\
\text { proposed } \\
\text { system cannot } \\
\text { detect properly. }\end{array}$ & $\begin{array}{l}\text { It is possible to } \\
\text { apply adequate } \\
\text { methods of deep } \\
\text { learning-based } \\
\text { object } \\
\text { classification. }\end{array}$ \\
\hline $\begin{array}{l}\text { Akila, } \\
2019[45]\end{array}$ & $\begin{array}{l}\text { Optical } \\
\text { Character } \\
\text { Recognition } \\
\text { (OCR), } \\
\text { Recursive sub- } \\
\text { divisions }\end{array}$ & English & $\begin{array}{l}\text { Private } \\
\text { dataset }\end{array}$ & $\begin{array}{l}\text { Achieved } \\
\text { higher } \\
\text { rates. }\end{array}$ & $\begin{array}{l}\text { This type of } \\
\text { technology } \\
\text { involves } \\
\text { identifying } \\
\text { vehicles that } \\
\text { are } \\
\text { unknown. }\end{array}$ & $\begin{array}{l}\text { There is no } \\
\text { classification } \\
\text { between the } \\
\text { customer and } \\
\text { the visitor in } \\
\text { this system. }\end{array}$ & $\begin{array}{l}\text { In the future, to } \\
\text { identify the visitor, } \\
\text { a separate scanner } \\
\text { will be installed. }\end{array}$ \\
\hline $\begin{array}{l}\text { Laroca, } \\
2018 \text { [47] }\end{array}$ & $\begin{array}{l}\text { Fast-YOLO, } \\
\text { YOLOv2, and } \\
\text { CNN }\end{array}$ & English & $\begin{array}{l}\text { SSIG and } \\
\text { UFPR-ALPR. }\end{array}$ & $\begin{array}{c}\text { SSIG: } \\
93.53 \% \text {, } \\
\text { UFPR: } \\
78.33 \%\end{array}$ & & $\begin{array}{l}\text { For certain real- } \\
\text { world ALPR } \\
\text { applications, } \\
\text { this outcome is } \\
\text { still not } \\
\text { acceptable. }\end{array}$ & $\begin{array}{l}\text { In the future, } \\
\text { character } \\
\text { segmentation and } \\
\text { recognitions } \\
\text { techniques can be } \\
\text { improved. }\end{array}$ \\
\hline $\begin{array}{l}\text { Gupta, } \\
2018[41]\end{array}$ & $\begin{array}{l}\text { Progressive } \\
\text { Growing of } \\
\text { Generative } \\
\text { Adversarial } \\
\text { Networks } \\
\text { (PGGANs) }\end{array}$ & English & $\begin{array}{l}\text { American } \\
\text { license plate } \\
\text { dataset }\end{array}$ & $\begin{array}{c}\text { More } \\
\text { than } 90 \%\end{array}$ & & $\begin{array}{l}\text { Quality of } \\
\text { synthesized } \\
\text { images suffers } \\
\text { when there are } \\
\text { too few samples } \\
\text { of a given style } \\
\text { in the training } \\
\text { data. }\end{array}$ & $\begin{array}{l}\text { This system can be } \\
\text { used in more } \\
\text { complex scene text } \\
\text { synthesis. }\end{array}$ \\
\hline $\begin{array}{l}\text { Kashyap, } \\
2018 \text { [56] }\end{array}$ & $\begin{array}{l}\text { Image } \\
\text { processing } \\
\text { techniques, } \\
\text { OCR }\end{array}$ & English & & $82.6 \%$ & & & $\begin{array}{l}\text { Multi-level genetic } \\
\text { algorithms can be } \\
\text { added for further } \\
\text { improvement. }\end{array}$ \\
\hline $\begin{array}{l}\text { Türkyllm } \\
\text { az, 2017 } \\
{[15]}\end{array}$ & $\begin{array}{l}\text { Edge-based } \\
\text { method and } \\
\text { three-layer } \\
\text { feedforward } \\
\text { ANN }\end{array}$ & English & $\begin{array}{l}\text { Their own } \\
\text { database } \\
\text { contains } 357 \\
\text { images }\end{array}$ & $97 \%$ & $\begin{array}{l}\text { The } \\
\text { developed } \\
\text { system } \\
\text { performs in } \\
\text { real-time. }\end{array}$ & & $\begin{array}{l}\text { Advance image } \\
\text { processing } \\
\text { techniques can be } \\
\text { applied. }\end{array}$ \\
\hline $\begin{array}{l}\text { Cheang, } \\
2017 \text { [44] }\end{array}$ & $\begin{array}{l}\text { CNN and RNN } \\
\text { (Recurrent } \\
\text { Neural } \\
\text { Network), }\end{array}$ & English & $\begin{array}{l}\text { Their own } \\
\text { Malaysian } \\
\text { VLP dataset } \\
\text { contains } 2713 \\
\text { images }\end{array}$ & $95.1 \%$ & $\begin{array}{l}\text { This system } \\
\text { performs in } \\
\text { real time. }\end{array}$ & & 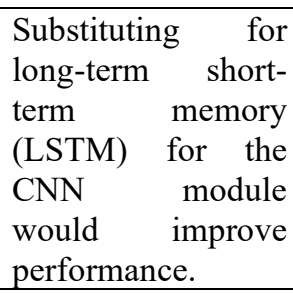 \\
\hline $\begin{array}{l}\text { Mondal, } \\
2017 \text { [11] }\end{array}$ & $\begin{array}{l}\text { CNN based } \\
\text { self-synthesized } \\
\text { feature learning } \\
\text { algorithm }\end{array}$ & English & $\begin{array}{l}\text { Their own } \\
\text { dataset } \\
\text { contains } 800 \\
\text { images }\end{array}$ & $90 \%$ & $\begin{array}{l}\text { This system } \\
\text { runs on } \\
\text { automation. }\end{array}$ & & $\begin{array}{l}\text { System } \\
\text { performance can be } \\
\text { done in real-time. }\end{array}$ \\
\hline $\begin{array}{l}\text { Wang, } \\
2017[42]\end{array}$ & $\begin{array}{l}\text { GAN } \\
\text { (Generative } \\
\text { Adversarial } \\
\text { Networks), } \\
\text { DCNN, BRNN } \\
\text { (bidirectional } \\
\text { recurrent neural } \\
\text { network), } \\
\text { LSTM (long } \\
\text { short-term } \\
\text { memory) }\end{array}$ & Chinese & $\begin{array}{l}\text { Dataset1 } \\
\text { contains } \\
203774 \\
\text { images and } \\
\text { dataset2 } \\
\text { contains } \\
\text { 45139 images }\end{array}$ & $89.4 \%$ & $\begin{array}{l}\text { The } \\
\text { significance } \\
\text { of GAN is } \\
\text { magnified } \\
\text { when real } \\
\text { annotated } \\
\text { data is } \\
\text { limited. }\end{array}$ & & $\begin{array}{l}\text { Accuracy can be } \\
\text { improved in the } \\
\text { future. }\end{array}$ \\
\hline
\end{tabular}




\begin{tabular}{|l|l|l|l|l|l|l|l|}
\hline $\begin{array}{l}\text { Pechiam } \\
\text { mal, } \\
2017[57]\end{array}$ & $\begin{array}{l}\text { Image } \\
\text { Processing } \\
\text { Techniques }\end{array}$ & English & & $85 \%$ & $\begin{array}{l}\text { Low } \\
\text { processing } \\
\text { time. }\end{array}$ & $\begin{array}{l}\text { An influential } \\
\text { ANPR framework } \\
\text { can use used to } \\
\text { manage multi-style } \\
\text { plates. }\end{array}$ \\
\hline
\end{tabular}

\section{Related Works on Vehicle Number Plate Detection and Recognition Techniques}

In [61], a new system for detecting and recognizing the Indian vehicle number plate has been suggested by Varma that can compete with noisy, low-light, cross-angled, non-standard font number plates. This work uses many image processing techniques in the pre-processing stage, such as morphological transformation, Gaussian smoothing, and Gaussian thresholding. They have used the K-nearest neighbor (KNN) approach for recognizing the character. They have stated that their proposed system achieved $98.02 \%$ accuracy for vehicle number plate detection and $96.22 \%$ accuracy for character recognition.

In [62], Automatic Number Plate Detection (ANPD) and Automatic Number Plate Recognition (ANPR) systems were intended for the detection and recognition of vehicle number plates in the research of Yaseen. A new realistic vehicle image dataset for three cities, called North Iraq-Vehicle Images (NI-VI), has been presented (Duhok, Erbil, and Sulaimani). Three types of images, such as rotated, scaled, and translated, are included in the collection of data.

In [63], the latest approach to identify and recognize the license plate centered on a hybrid feature extraction model and BPNN, which is adaptable in poor lighting and complex contexts, was introduced by Xie. They reported that the accuracy achieved by the proposed technique is $97.7 \%$ and the processing time is $46.1 \mathrm{~ms}$.

In [64], a full unregulated scenario ALPR method has been proposed and implemented a new Convolutional Neural Networks $(\mathrm{CNN})$ to detect as well as recognize the number plate of the vehicle in an input image. To identify the character, they used OCR technology. They have reported that an average accuracy of more than $80 \%$ was reached by the proposed method.

A systematic technique was developed in [65] for the identification, segmentation, and recognition of characters within the license plate. To extract the characters from the number plate, they utilized Hough Transform and horizontal projection. They ensured that more than $90 \%$ higher accuracy was reached by the proposed system.

In [66], a Bangla license plate recognition system based on Convolutional Neural Networks was suggested by Shaifur Rahman, which could be used for various purposes, such as roadside assistance, vehicle license status identification. Six CNN layers and a fully connected layer were used by the authors for training. They have reported that $89 \%$ testing precision was achieved by the proposed Bangla license plate recognition system (BLPRS).

Table 5: Summary of the proposed vehicle number plate detection and recognition techniques.

\begin{tabular}{|c|c|c|c|c|c|c|c|}
\hline $\begin{array}{c}\text { First } \\
\text { Author \& } \\
\text { Year }\end{array}$ & $\begin{array}{c}\text { Detection \& } \\
\text { Recognition } \\
\text { Methods }\end{array}$ & $\begin{array}{l}\text { Recognition } \\
\text { Character }\end{array}$ & Datasets & Accuracy & Advantages & Limitations & Future Opportunities \\
\hline $\begin{array}{c}\text { Alam, } \\
2021[68]\end{array}$ & $\begin{array}{l}\text { CNN and Deep } \\
\text { Learning }\end{array}$ & Bengali & $\begin{array}{l}\text { VLPR } \\
\text { vehicle } \\
\text { dataset }\end{array}$ & $98.2 \%$ & $\begin{array}{l}\text { This system is } \\
\text { used for smart } \\
\text { cities. }\end{array}$ & & $\begin{array}{l}\text { The system can be } \\
\text { used for LP in other } \\
\text { languages. }\end{array}$ \\
\hline $\begin{array}{c}\text { Varma, } \\
2020[61]\end{array}$ & $\begin{array}{l}\text { Morphological } \\
\text { transformation, } \\
\text { Gaussian } \\
\text { smoothing, } \\
\text { Gaussian } \\
\text { thresholding, } \\
\text { and KNN }\end{array}$ & Indian & $\begin{array}{l}\text { Private } \\
\text { dataset }\end{array}$ & $\begin{array}{l}\text { Detection: } \\
98.02 \% \\
\text { and } \\
\text { Recogniti } \\
\text { on: } \\
96.22 \%\end{array}$ & & $\begin{array}{l}\text { When font size } \\
\text { of LP is smaller, } \\
\text { the suggested } \\
\text { method gave } \\
\text { poor prediction. }\end{array}$ & $\begin{array}{l}\text { In the future } \\
\text { Convolutional Neural } \\
\text { Network can be } \\
\text { integrated } \\
\text { incorporates that } \\
\text { detection both } \\
\text { recognition into and } \\
\text { single structure. }\end{array}$ \\
\hline $\begin{array}{c}\text { Onim, } \\
2020[69]\end{array}$ & $\begin{array}{c}\text { YOLOv4, } \\
\text { CNN, } \\
\text { Tesseract } \\
\text { (OCR engine) }\end{array}$ & Bengali & $\begin{array}{l}\text { Private } \\
\text { dataset }\end{array}$ & $90.50 \%$ & & $\begin{array}{l}\text { When it is under } \\
\text { shade or under } \\
\text { direct sunlight, } \\
\text { their proposed } \\
\text { system fails to } \\
\text { detect VLP. }\end{array}$ & $\begin{array}{l}\text { To reduce the effects } \\
\text { of blurry VLP and by } \\
\text { deploying } \\
\text { preprocessing, to } \\
\text { overcome the } \\
\text { deterrents of OCR. }\end{array}$ \\
\hline $\begin{array}{l}\text { Yaseen, } \\
2019[62]\end{array}$ & $\begin{array}{l}\text { ANPD and } \\
\text { ANPR } \\
\text { technologies. }\end{array}$ & Arabic & $\begin{array}{l}\text { North } \\
\text { Iraq } \\
\text { (NI-VI) } \\
\text { dataset }\end{array}$ & ----- & $\begin{array}{l}\text { Provides a } \\
\text { realistic } \\
\text { dataset. }\end{array}$ & $\begin{array}{l}\text { The proposed } \\
\text { data set is } \\
\text { connected to } \\
\text { only north Iraq } \\
\text { vehicle license } \\
\text { plates. }\end{array}$ & $\begin{array}{l}\text { In future, the research } \\
\text { for the entire country } \\
\text { of Iraq can be } \\
\text { strengthened. }\end{array}$ \\
\hline
\end{tabular}




\begin{tabular}{|c|c|c|c|c|c|c|c|}
\hline $\begin{array}{l}\text { Xie, } 2018 \\
\text { [63] }\end{array}$ & $\begin{array}{l}\text { Feature } \\
\text { extraction } \\
\text { model and } \\
\text { BPNN }\end{array}$ & Chinese & $\begin{array}{l}\text { Private } \\
\text { dataset }\end{array}$ & $97.7 \%$ & $\begin{array}{l}\text { This system to } \\
\text { be helpful for } \\
\text { real time } \\
\text { applications. }\end{array}$ & & $\begin{array}{l}\text { With RFID devices } \\
\text { and Bluetooth devices, } \\
\text { this work can be } \\
\text { enhanced to better } \\
\text { precision of } \\
\text { recognition. }\end{array}$ \\
\hline $\begin{array}{l}\text { Hossen, } \\
2018[67]\end{array}$ & $\begin{array}{l}\text { Horizontal \& } \\
\text { Vertical } \\
\text { projections, } \\
\text { Back- } \\
\text { propagation } \\
\text { feed-forward } \\
\text { neural } \\
\text { networks }\end{array}$ & Bangla & $\begin{array}{l}\text { Private } \\
\text { dataset }\end{array}$ & $90.5 \%$ & $\begin{array}{l}\text { Proposed } \\
\text { method is very } \\
\text { effective for } \\
\text { different } \\
\text { viewpoints, } \\
\text { illumination } \\
\text { conditions, and } \\
\text { small } \\
\text { distances. }\end{array}$ & & $\begin{array}{l}\text { In the future, accuracy } \\
\text { can be improved. }\end{array}$ \\
\hline $\begin{array}{l}\text { Shaifur } \\
\text { Rahman, } \\
2018 \text { [66] }\end{array}$ & $\begin{array}{l}\text { Convolution } \\
\text { al Neural } \\
\text { Networks } \\
(\mathrm{CNN})\end{array}$ & Bangla & $\begin{array}{l}\text { Their own } \\
\text { dataset }\end{array}$ & $89 \%$ & & $\begin{array}{l}\text { For smaller } \\
\text { memory and } \\
\text { computational } \\
\text { power, the } \\
\text { proposed } \\
\text { system faced } \\
\text { some } \\
\text { limitations. }\end{array}$ & $\begin{array}{l}\text { With a higher number } \\
\text { of function maps and } \\
\text { more layers, the } \\
\text { proposed framework } \\
\text { can be augmented. }\end{array}$ \\
\hline $\begin{array}{l}\text { Silva, } \\
2018[64]\end{array}$ & CNN, OCR & English & $\begin{array}{c}\text { AOLP } \\
\text { Road } \\
\text { Patrol, } \\
\text { SSIG, } \\
\text { OpenALP } \\
\text { R, CD- } \\
\text { HARD } \\
\end{array}$ & $\begin{array}{l}\text { Higher } \\
\text { than } 80 \% \text {. }\end{array}$ & & & $\begin{array}{l}\text { This research can be } \\
\text { extended to detect } \\
\text { motorcycle LPs. }\end{array}$ \\
\hline $\begin{array}{l}\text { Prabhakar } \\
, 2014 \\
{[65]}\end{array}$ & $\begin{array}{l}\text { Hough } \\
\text { Transform, } \\
\text { Horizontal } \\
\text { Projection }\end{array}$ & English & $\begin{array}{l}\text { Private } \\
\text { dataset }\end{array}$ & $94 \%$ & $\begin{array}{l}\text { This system } \\
\text { effectively } \\
\text { reduces the } \\
\text { computation } \\
\text { time. }\end{array}$ & & $\begin{array}{l}\text { In the future, the } \\
\text { system can be } \\
\text { developed at a low } \\
\text { cost in real-time. }\end{array}$ \\
\hline
\end{tabular}

In [67], a novel method for detecting the Bangla license plate was proposed by Hossen Firstly, the location of vehicles is determined. Next, compare the RGB intensity of the plate with the vehicle's license and material properties to localize the license plate area. Thereafter, they have separated horizontal projectionbased registration using the required threshold value. After that, using vertical projection of the same threshold value, the characters and the digits are also separated. Finally, using the backpropagation feed-forward neural networks, the characters and digits have been established. Authors have reported that $93.89 \%$, $98.22 \%$, and $92.77 \%$ respectively are the success rate of the license plate identification, segmentation, and recognition process. In Figure 11, the proposed method is shown.

In [68], a method using Convolutional Neural Network (CNN) and Deep Learning strategies to identify and recognize vehicle number plates in the Bengali language has been suggested by Alam. A super-resolution technique has been used with the CNN in the recognition portion to reconstruct the pixel quality of the input image. Each number plate character is segmented using a bounding box technique. 700 vehicles were appointed to test the experiment outcomes. They reported that in the validation set, CNN gained $98.2 \%$ accuracy and obtained $98.1 \%$ accuracy in the evaluation set and the error rate was $1.8 \%$. Their proposed system can be connected to a cloud-based system where all registered vehicle numbers will be stored.

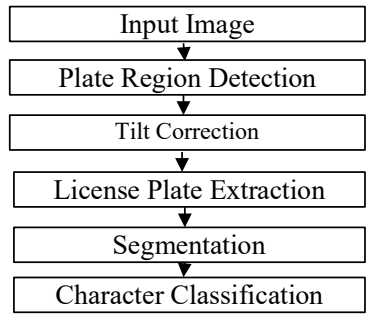

Figure 11: Overview of the proposed method by Hossen [67]

In [69], a prototype of YOLOv4 object detection has been implemented in which the Convolutional Neural Network (CNN) is trained and configured to detect the vehicle's Bengali license plate and to recognize characters from the detected license plates using Tesseract (OCR engine). They reported that the model of license plate detection is trained at $90.50 \%$ to mean average accuracy (mAP) and recall of 0.86 during training.

An overview of the vehicle number plate detection as well as recognition techniques is shown in Table 5. This table has been sorted based on the year and accuracy. 
The existing methods for the identification and recognition of vehicle license plates have been classified based on accuracy that is shown in Figure 12.

\section{Conclusion}

This study paper presents a concise description of the vehicle number plate detection as well as recognition techniques used for effective traffic monitoring and observation of the reliability of the methods. In the construction of a smart transport network, vehicle number plate detection, as well as a recognition system, plays an important role. Although identification of vehicle number plates has always been a difficult proposition for certain reasons including changes in lighting, glare, non-uniform type of license plate, different styles, and color effects in the environment. Recognitions may also use some image processing techniques in conjunction with neural networks to identify the number plate characters, moving distance images, numbering schemes, angled or side-view images. In this study, the methods of vehicle number plate detection and recognition have been classified based on accuracy. In the future, the preference is to use high-resolution cameras with an improved number of frames for better performance and effective license plate recognition. The classification section can be further improved with the complexity, speed, and chronological order. This study includes a comprehensive evaluation of the progress and future patterns in the identification and recognition of recent vehicle number plates which could be of value to researchers interested in such development.

\section{Conflict of Interest}

There is no conflict of interest reported between the authors.

\section{Acknowledgment}

We are thankful to the Department of Computer Science and Engineering, Jahangirnagar University.

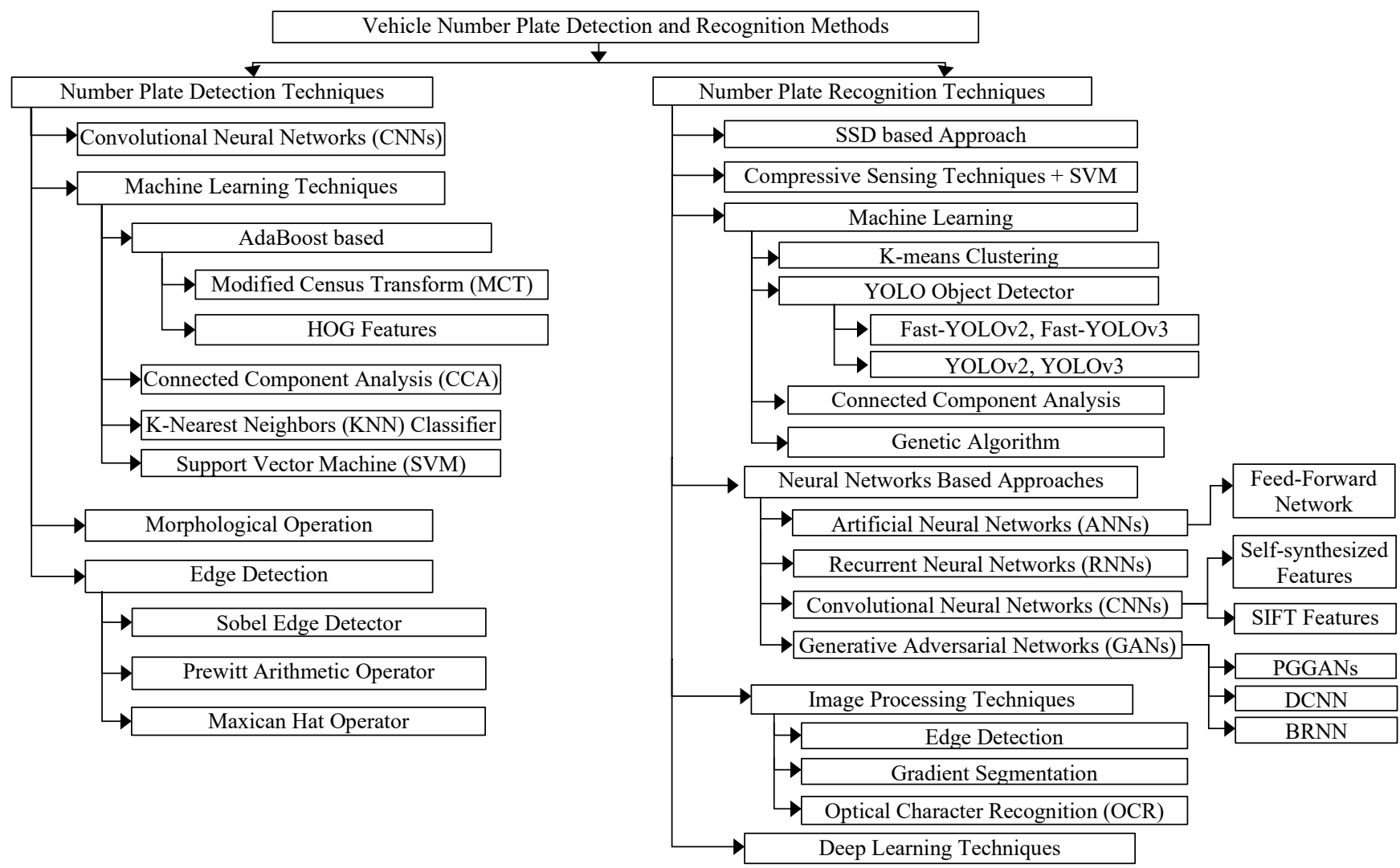

Figure 12: Existing frameworks for previous research.

\section{References}

[1] P.R. Sanap, S.P. Narote, "License plate recognition system for Indian vehicles," AIP Conference Proceedings, 1324, 130-134, 2010 (December), doi:10.1063/1.3526175.

[2] S. Ghasempour, “Automatic License Plate Recognition (ALPR)," 11(21), 2015.

[3] Z. Akhtar, R. Ali, "Automatic Number Plate Recognition Using Random Forest Classifier," SN Computer Science, 1(3), 1-9, 2020, doi:10.1007/s42979-020-00145-8.
[4] K. Sonavane, B. Soni, U. Majhi, "Survey on Automatic Number Plate Recognition (ANR)," International Journal of Computer Applications, 125(6), 1-4, 2015, doi:10.5120/ijca2015905920.

[5] S. Miyata, K. Oka, "Automated license plate detection using a support vector machine," 2016 14th International Conference on Control, Automation, Robotics and Vision, ICARCV 2016, 13-15, 2016 , doi:10.1109/ICARCV.2016.7838653.

[6] D. Bhardwaj, S. Mahajan, "Review Paper on Automated Number Plate Recognition Techniques," International Journal of Emerging Research in Management \&Technology, 6(15), 2278-9359, 2015. 
[7] M.T. Shahed, M.R.I. Udoy, B. Saha, A.I. Khan, S. Subrina, “Automatic Bengali number plate reader," IEEE Region 10 Annual International Conference, Proceedings/TENCON, 2017-Decem, 1364-1368, 2017, doi:10.1109/TENCON.2017.8228070.

[8] Regtransfers.co.uk, "Number plates rules". [Online]. Available: https://www.regtransfers.co.uk/acrylic-number-plates/number-plates-rules

[9] A. Bhujbal, D. Mane, "A survey on deep learning approaches for vehicle and number plate detection," International Journal of Scientific and Technology Research, 8(12), 1378-1383, 2019.

[10] I.M. Gorovyi, I.O. Smirnov, "Robust number plate detector based on stroke width transform and neural network," 2015 Signal Processing Symposium, SPSympo 2015, 2015, doi:10.1109/SPS.2015.7168289.

[11] M. Mondal, P. Mondal, N. Saha, P. Chattopadhyay, "Automatic number plate recognition using CNN based self synthesized feature learning," 2017 IEEE Calcutta Conference, CALCON 2017 - Proceedings, 2018-Janua, 378381, 2018, doi:10.1109/CALCON.2017.8280759.

[12] A. Menon, B. Omman, "Detection and Recognition of Multiple License Plate from Still Images," 2018 International Conference on Circuits and Systems in Digital Enterprise Technology, ICCSDET 2018, 2018, doi:10.1109/ICCSDET.2018.8821138.

[13] M.A. Uddin, J.B. Joolee, S.A. Chowdhury, "Bangladeshi Vehicle Digital License Plate Recognition for Metropolitan Cities Using Support Vector Machine," Proc. International Conference on Advanced Information and Communication Technology, 2016.

[14] R. Boliwala, M. Pawar, "Automatic number plate detection for varying illumination conditions," International Conference on Communication and Signal Processing, ICCSP 2016, 658-661, 2016, doi:10.1109/ICCSP.2016.7754224.

[15] I. Türkyilmaz, K. Kaçan, "License plate recognition system using artificial neural networks,” ETRI Journal, 39(2), 163-172, 2017, doi:10.4218/etrij.17.0115.0766.

[16] S. Saha, "A Review on Automatic License Plate Recognition System," ArXiv, 2019

[17] R. Islam, M.R. Islam, K.H. Talukder, "An efficient method for extraction and recognition of bangla characters from vehicle license plates," Multimedia Tools and Applications, 79(27-28), 20107-20132, 2020, doi:10.1007/s11042-020-08629-8.

[18] G.R. Gonçalves, S.P.G. da Silva, D. Menotti, W.R. Schwartz, "Benchmark for license plate character segmentation," Journal of Electronic Imaging, 25(5), 053034, 2016, doi:10.1117/1.jei.25.5.053034.

[19] G.R. Jadhav, K.J. Karande, "Automatic Vehicle Number Plate Recognition for Vehicle Parking Management System,” 16(April 2014), 978-93, 2014.

[20] L. Shantha, B. Sathiyabhama, T.K. Revathi, N. Basker, R.B. Vinothkumar, "Tracing of Vehicle Region and Number Plate Detection using Deep Learning," International Conference on Emerging Trends in Information Technology and Engineering, Ic-ETITE 2020, (2018), 2018-2021, 2020, doi:10.1109/ic-ETITE47903.2020.357.

[21] C. Patel, D. Shah, A. Patel, "Automatic Number Plate Recognition System (ANPR): A Survey," International Journal of Computer Applications, 69(9), 21-33, 2013, doi:10.5120/11871-7665.

[22] D. Wazalwar, E. Oruklu, J. Saniie, "Design flow for robust license plate localization," IEEE International Conference on Electro Information Technology, 2011, doi:10.1109/EIT.2011.5978590.

[23] R. Chen, Y. Luo, "An Improved License Plate Location Method Based On Edge Detection," Physics Procedia, 24, 1350-1356, 2012, doi:10.1016/j.phpro.2012.02.201.

[24] K. Tejas, K. Ashok Reddy, D. Pradeep Reddy, M. Rajesh Kumar, "Efficient licence plate detection by unique edge detection algorithm and smarter interpretation through IoT," ArXiv, 2017.

[25] Nick Efford. "Morphological image processing", Chapter 11, Digital Image Processing: A Practical Introduction Using JavaTM. Pearson Education, 2000. [Online]. Available:

https://www.cs.auckland.ac.nz/courses/compsci773s1c/lectures/ImageProc essing-html/topic4.htm

[26] J. Yepez, S.B. Ko, "Improved license plate localisation algorithm based on morphological operations," IET Intelligent Transport Systems, 12(6), 542549, 2018, doi:10.1049/iet-its.2017.0224.
[27] N. Eswar, Dr. D. Gowri Shankar Reddy, "Morphological Operation based Vehicle Number Plate Detection," International Journal of Engineering Research And, V9 (02), 428-433, 2020, doi:10.17577/ijertv9is020064.

[28] N.O. Yaseen, S.G.S. Al-Ali, A. Sengur, "An Efficient Model for Automatic Number Plate Detection using HOG Feature from New North Iraq Vehicle Images Dataset," 1st International Informatics and Software Engineering Conference: Innovative Technologies for Digital Transformation, IISEC 2019 - Proceedings, 2019, doi:10.1109/UBMYK48245.2019.8965573.

[29] K.D. Ban, Y. Yoon, H.S. Yoon, J. Kim, "Number detection in natural image with boosting classifier," 2012 9th International Conference on Ubiquitous Robots and Ambient Intelligence, URAI 2012, (Urai), 525-526, 2012, doi:10.1109/URAI.2012.6463060.

[30] M. Molina-Moreno, I. Gonzalez-Diaz, F. Diaz-De-Maria, "Efficient ScaleAdaptive License Plate Detection System," IEEE Transactions on Intelligent Transportation Systems, 20(6), 2109-2121, 2019, doi:10.1109/TITS.2018.2859035.

[31] S. Babbar, S. Kesarwani, N. Dewan, K. Shangle, S. Patel, "A New Approach for Vehicle Number Plate Detection," 2018 11th International Conference on Contemporary Computing, IC3 2018, 1-6, 2018, doi:10.1109/IC3.2018.8530600.

[32] K. H. P. Akshay lepcha, S.R.Adithya, G.Anuraag, K.Sathish,I. "A Novel Methodology for License Plate Detection Using Knn Classifier," Journal, F.O.R. Advanced, A. Sciences, "ISSN NO: 2394-8442, 5(3), 582-586.

[33] G. Lokesh, S. Yogesh, K. Prasad, R. Akash," Review Paper on Automatic Vehicle Number Plate Detection and Recognition Using Image Processing", International Journal of Advance Engineering and Research, 47-50, 2017.

[34] H. Saghaei, "Proposal for Automatic License and Number Plate Recognition System for Vehicle Identification," International Conference on New Research Achievements in Electrical and Computer Engineering Proposal, 2016.

[35] A. Bajpai, "A Survey On Automatic Vehicle Number Plate Detection System," International Journal of Computer Science Trends and Technology (IJCST), 5(2), 291-297, 2017.

[36] I.V. Pustokhina, D.A. Pustokhin, J.J.P.C. Rodrigues, D. Gupta, A. Khanna, K. Shankar, C. Seo, G.P. Joshi, "Automatic Vehicle License Plate Recognition Using Optimal K-Means with Convolutional Neural Network for Intelligent Transportation Systems," IEEE Access, 8, 92907-92917, 2020, doi:10.1109/ACCESS.2020.2993008.

[37] X. Yang, X. Wang, "Recognizing License Plates in Real-Time," 2019.

[38] Y.G. Qian, D.F. Ma, B. Wang, J. Pan, J.M. Wang, J.H. Chen, W.J. Zhou, J.S. Lei, "Spot evasion attacks: Adversarial examples for license plate recognition systems with convolutional neural networks," ArXiv, 2019.

[39] L. Zhu, S. Wang, C. Li, Z. Yang, "License Plate Recognition in Urban Road Based on Vehicle Tracking and Result Integration," Journal of Intelligent Systems, 29(1), 1587-1597, 2020, doi:10.1515/jisys-2018-0446.

[40] Y. Lee, J. Lee, H. Ahn, M. Jeon, "SNIDER: Single noisy image denoising and rectification for improving license plate recognition," Proceedings 2019 International Conference on Computer Vision Workshop, ICCVW 2019, 1017-1026, 2019, doi:10.1109/ICCVW.2019.00131.

[41] M. Gupta, A. Kumar, S. Madhvanath, "Parametric Synthesis of Text on Stylized Backgrounds using PGGANs," ArXiv, 2018.

[42] X. Wang, Z. Man, M. You, C. Shen, "Adversarial generation of training examples: Applications to moving vehicle license plate recognition," ArXiv, $1-13,2017$.

[43] L. Zhang, P. Wang, H. Li, Z. Li, C. Shen, Y. Zhang, "A Robust Attentional Framework for License Plate Recognition in the Wild," ArXiv, 1-10, 2020, doi:10.1109/tits.2020.3000072.

[44] T.K. Cheang, Y.S. Chong, Y.H. Tay, "Segmentation-free Vehicle License Plate Recognition using ConvNet-RNN," ArXiv, 2017.

[45] K. Akila, B. Sabitha, R. Jayamurugan, M. Teveshvar, N. Vignesh, "Automated license plate recognition system using computer vision," International Journal of Engineering and Advanced Technology, 8(6), 18781881, 2019, doi:10.35940/ijeat.F7901.088619.

[46] ODSC- Open Data Science, "Overview of the YOLO Object Detection Algorithm" September 25, 2018. [Online]. Available: https://medium.com/@ODSC/overview-of-the-yolo-object-detectionalgorithm-

7b52a745d3e0\#: :text=YOLO\%20uses\%20a\%20totally\%20different,and\% 20probabilities\%20for\%20each\%20region. 
[47] R. Laroca, E. Severo, L.A. Zanlorensi, L.S. Oliveira, G.R. Goncalves, W.R. Schwartz, D. Menotti, "A Robust Real-Time Automatic License Plate Recognition Based on the YOLO Detector," Proceedings of the International Joint Conference on Neural Networks, 2018-July, 2018, doi:10.1109/IJCNN.2018.8489629.

[48] R. Laroca, L.A. Zanlorensi, G.R. Gonçalves, E. Todt, W.R. Schwartz, D. Menotti, "An efficient and layout-independent automatic license plate recognition system based on the yolo detector," ArXiv, 2019.

[49] W. Min, X. Li, Q. Wang, Q. Zeng, Y. Liao, "New approach to vehicle license plate location based on new model YOLO-L and plate pre-identification," IET Image Processing, 13(7), 1041-1049, 2019, doi:10.1049/ietipr.2018.6449.

[50] C. Henry, S.Y. Ahn, S.W. Lee, "Multinational License Plate Recognition Using Generalized Character Sequence Detection," IEEE Access, 8, 3518535199, 2020, doi:10.1109/ACCESS.2020.2974973.

[51] W. Weihong, T. Jiaoyang, "Research on License Plate Recognition Algorithms Based on Deep Learning in Complex Environment," IEEE Access, 8, 91661-91675, 2020, doi:10.1109/ACCESS.2020.2994287.

[52] A. Elihos, B. Balci, B. Alkan, Y. Artan, "Deep learning based segmentation free license plate recognition using roadway surveillance camera images," ArXiv, 2019.

[53] L. Yao, Y. Zhao, J. Fan, M. Liu, J. Jiang, Y. Wan, "Research and Application of License Plate Recognition Technology Based on Deep Learning," Journal of Physics: Conference Series, 1237(2), 2019, doi:10.1088/17426596/1237/2/022155.

[54] M.Y. Arafat, A.S.M. Khairuddin, R. Paramesran, "Connected component analysis integrated edge based technique for automatic vehicular license plate recognition framework," IET Intelligent Transport Systems, 14(7), 712-723, 2020, doi:10.1049/iet-its.2019.0006.

[55] G. Kumar, A. Barman, M. Pal, "License Plate Tracking using Gradient based Segmentation," IEEE Region 10 Annual International Conference, Proceedings/TENCON, 2019-Octob, 1737-1740, 2019, doi:10.1109/TENCON.2019.8929688.

[56] A. Kashyap, B. Suresh, A. Patil, S. Sharma, A. Jaiswal, "Automatic Number Plate Recognition," Proceedings - IEEE 2018 International Conference on Advances in Computing, Communication Control and Networking, ICACCCN 2018, 838-843, 2018, doi:10.1109/ICACCCN.2018.8748287.

[57] B. Pechiammal, J.A. Renjith, "An efficient approach for automatic license plate recognition system," ICONSTEM 2017 - Proceedings: 3rd IEEE International Conference on Science Technology, Engineering and Management, 2018-Janua, 121-129, 2017, doi:10.1109/ICONSTEM.2017.8261267.

[58] S.U. Rehman, M. Ahmad, A. Nawaz, T. Ali, "An Efficient Approach for Vehicle Number Plate Recognition in Pakistan," The Open Artificial Intelligence Journal, 6(1), 12-21, 2020, doi:10.2174/1874061802006010012.

[59] A. Jokić, N. Vuković, "License Plate Recognition with Compressive Sensing Based Feature Extraction," ArXiv, 1-4, 2019.

[60] B.B. Yousif, M.M. Ata, N. Fawzy, M. Obaya, "Toward an Optimized Neutrosophic k-Means with Genetic Algorithm for Automatic Vehicle License Plate Recognition (ONKM-AVLPR)," IEEE Access, 8, 4928549312, 2020, doi:10.1109/ACCESS.2020.2979185.

[61] P.R.K. Varma, S. Ganta, B. Hari Krishna, P. Svsrk, “A Novel Method for Indian Vehicle Registration Number Plate Detection and Recognition using Image Processing Techniques," Procedia Computer Science, 167(2019), 2623-2633, 2020, doi:10.1016/j.procs.2020.03.324.

[62] N.O. Yaseen, S.G.S. Al-Ali, A. Sengur, "Development of New Anpr Dataset for Automatic Number Plate Detection and Recognition in North of Iraq," 1st International Informatics and Software Engineering Conference: Innovative Technologies for Digital Transformation, IISEC 2019 Proceedings, 2019, doi:10.1109/UBMYK48245.2019.8965512.

[63] F. Xie, M. Zhang, J. Zhao, J. Yang, Y. Liu, X. Yuan, “A Robust License Plate Detection and Character Recognition Algorithm Based on a Combined Feature Extraction Model and BPNN," Journal of Advanced Transportation, 2018, 2018, doi:10.1155/2018/6737314.

[64] S.M. Silva, C.R. Jung, "License plate detection and recognition in unconstrained scenarios," Lecture Notes in Computer Science (Including Subseries Lecture Notes in Artificial Intelligence and Lecture Notes in Bioinformatics), 11216 LNCS, 593-609, 2018, doi:10.1007/978-3-03001258-8_36.
[65] P. Prabhakar, P. Anupama, S.R. Resmi, "Automatic vehicle number plate detection and recognition," 2014 International Conference on Control, Instrumentation, Communication and Computational Technologies, ICCICCT 2014, 185-190, 2014, doi:10.1109/ICCICCT.2014.6992954.

[66] M.M. Shaifur Rahman, M.S. Nasrin, M. Mostakim, M. Zahangir Alom, "Bangla license plate recognition using Convolutional Neural Networks (CNN)," ArXiv, 2018.

[67] M.K. Hossen, A.C. Roy, M.S.A. Chowdhury, M.S. Islam, K. Deb, "License Plate Detection and Recognition System based on Morphological Approach and Feed-Forward Neural Network," International Journal of Computer Science and Network Security, 18(5), 36-45, 2018.

[68] N.-A.- Alam, M. Ahsan, M.A. Based, J. Haider, "Intelligent System for Vehicles Number Plate Detection and Recognition Using Convolutional Neural Networks," Technologies, 9(1), 9, 2021, doi:10.3390/technologies9010009.

[69] M.S.H. Onim, M.I. Akash, M. Haque, R.I. Hafiz, "Traffic surveillance using vehicle license plate detection and recognition in bangladesh," ArXiv, (December), 2020. 